\title{
Detection by the guinea pig of acoustic stimulation and of electrical stimulation of the brain'
}

GEORGE M. GERKEN

UNIVERSITY OF VIRCINIA

A thresthold procedure using operant behaviorai techniques with positive reinforcement was detcloped after initial ef forts with avoidance behavioral procedures proved unsatisfactory. In the first of three experiments the operant threshold procedure was tested by determining masked auditory thresholds for trains of clicks. In a second experiment, similar techniques were used to measure thresholds for electrical stimulation of the brain. The last experiment, again an auditory problem, involved a determination of the absolute thresholds for trains of short noise bursts as a function of the time between bursts. Middle ear malfunction proved to be a morc severe problem than had been anticipated on the basts of reports in the literature. The threshold procedure, hou'ever, seems to be adequate for determination of absolute or masked thresholds with auditory or electrical stimuli.

The guinea pig has frequently been used in electrophysiological studies of the cochlea and lower auditory system. The varied vocal repertoire of the guinea pig, the obvious responsiveness of the animal to auditory stimuli, and the prominent temporal areas of its brain indicate its importance for psychoacoustic research.

The approach taken here is related to animal psychophysics and the neuropsychology of hearing. Three experiments were performed that were concerned with the measurement of threshold quantities. A procedure for threshold measurement in the guinea pig was developed in preliminary studies. Experiment 1 was conducted in order to test the procedure. In Experiment 2 , similar techniques were used to measure thresholds for electrical stimulation of the brain. The last experiment, again dealing with an auditory problem, involved a determination of the absolute thresholds for trains of short noise bursts as a function of the time between bursts. The animals used in all of the experiments were of mixed short-hair breeds and were generally pigmented.

\section{PRELIMINARY STUDIES}

In an attempt to use procedures often used with the cat (Watson, 1963; Diamond \& Neff, 1957), guinea pigs were trained in a shuttle box using an avoidance technique with sound as a warning stimulus and electric shock as the aversive stimulus. Training procedures with different shock intensities were used with different Ss but sessions with more than 70 to $80 \%$ successful avoidance trials were infrequent. Other Ss trained to respond by turning a paddle wheel or by pressing against one wall of the compartment to terminate the shock performed no better. It was concluded that the failure to avoid shock more consistentiy was the result of a competition between the learned active avoidance response and the passive avoidance response (freezing) more natural to the guinea pig. A similar conclusion was reached by Miller (1964). To avoid this competition of responses, operant conditioning techniques with positive, instead of negative, reinforcement were tried.

Although the guinea pig can be trained to press a lever, particularly a lever close to the floor of the cage, its performance when compared to the rat is quite poor. This would seem to be related to the ability of the rat and the inability of the guinea pig to manipulate objects with the forepaws. A lever to be raised by the snout of the animal was tried and would have been satisfactory except that the response latencies were often several seconds. The response that was finally selected was a lateral movement of the head requiring no physical contact with a response-device. The movement was detected by a response-device that was either a capacitanceoperated proximity-detector (Experiment 1) or a photocell-actuated relay (Experiments 2 and 3 ). The response required of the animal was the same in either case. A response was recorded when the animal moved its snout near a short plastic rod which extended out from the wall of the cage and which was mounted approximately $2.5 \mathrm{in}$, above the floor. Response latencies to an auditory stimulus were typically on the order of $1.5 \mathrm{sec}$. or less, and the response itself was learned during the first few minutes of training.

Water or vegetable juices functioned as reinforcers for the guinea pigs. It appeared at first that they could be run without deprivation using vegetable juice as a reinforcer, but the animals were not sufficiently motivated. Consequently water was used as a reinforcer and the animals were routinely deprived to, and maintained at, $80 \%$ of ad lib body weight. This level of deprivation produced satisfactory performance; less deprivation yielded inferior performance.

In these preliminary studies with avoidance and operant conditioning, over 40 Ss were used. In addition, it was determined with these animals that masked auditory thresholds could be obtained using the procedure described below.

\section{OPERANT THRESHOLD PROCEDURE}

Testing in all experiments was carried out in a plastic cage constructed of widely spaced plastic bars. The cage was constructed in this manner in order to minimize interference with sound coming from loud speakers located outside the cage. The plastic cage was contained in a 
Table 1 Experiments 1,2 , and 3 :

Summary of Procedural Details and Selected Behavioral Results

\begin{tabular}{|c|c|c|c|}
\hline \multirow[b]{2}{*}{$\begin{array}{l}\text { Procedure } \\
\text { or result }\end{array}$} & \multicolumn{3}{|c|}{ Experiment } \\
\hline & 1 & 2 & 3 \\
\hline Number of $5 \mathrm{~s}$ & & 3 & $\begin{array}{cc}\text { animal human } \\
2 & 2 \\
\end{array}$ \\
\hline S- interval & $\begin{array}{l}\text { Basic } 15 \text { sec. S- } \\
\text { interval aug- } \\
\text { mented by ran- } \\
\text { domly added per- } \\
\text { iods of } 3 \text { to } 20 \\
\text { sec. duration }\end{array}$ & $\begin{array}{l}15,20,25 \text {, or } 30 \\
\text { sec. in scrambled } \\
\text { order }\end{array}$ & $\begin{array}{l}15,20,25 \text {, or } 30 \\
\text { sec. in scrambled } \\
\text { order }\end{array}$ \\
\hline $\begin{array}{l}\text { Delay for } 5- \\
\text { response }\end{array}$ & $\begin{array}{l}\text { S- response re- } \\
\text { sets timer for } \\
\text { bosic } 15 \text { sec. S- } \\
\text { intervol to zero }\end{array}$ & $10 \mathrm{sec}$. & $\begin{array}{l}8,9,10,11 \text {, or } \\
15 \text { sec. in scram- } \\
\text { bled order }\end{array}$ \\
\hline $\begin{array}{l}\text { Number of } \\
\text { hits per } \\
\text { session }\end{array}$ & 40 & 60 & 60 \\
\hline S+ duration & $\begin{array}{l}5 \text { sec. maximum; } \\
\text { terminated by a } \\
\text { hit }\end{array}$ & $\begin{array}{l}3 \text { sec, maximum; } \\
\text { terminated by a } \\
\text { hit }\end{array}$ & $\begin{array}{l}\text { I sec. fixed } \\
\text { duration }\end{array}$ \\
\hline $\begin{array}{l}\text { Response } \\
\text { period }\end{array}$ & $\begin{array}{l}\text { Same as } \mathrm{S}_{+} \\
\text {duration }\end{array}$ & $\begin{array}{l}\text { Same as } S_{+} \\
\text {duration }\end{array}$ & $\begin{array}{l}3 \text { sec. maximum; } \\
\text { terminated by a } \\
\text { hit }\end{array}$ \\
\hline $\begin{array}{l}\text { Mean number } \\
\text { of } S-\text { respons- } \\
\text { es per session }\end{array}$ & & 106 & 16 \\
\hline $\begin{array}{l}\text { Mean latency, } \\
\text { given that a } \\
\text { hit occurred }\end{array}$ & $1.6 \mathrm{sec}$ & $1.1 \mathrm{sec}$. & $1.1 \mathrm{sec} . \quad 0.7 \mathrm{sec}$ \\
\hline
\end{tabular}

larger chamber with sand-filled double plywood walls 3 in. thick, covered on the inside with $1.5 \mathrm{in.}$ of soundabsorbent material.

The task of Swas to respond to an auditory or electrical stimulus ( $\left.S_{t}\right)$ by moving its snout near the responsedevice. A correct response (hit) was scored if $\mathrm{S}$ responded in an interval starting $0.2 \mathrm{sec}$. after the onset of $S+$ and lasting through the end of a response period of limited duration. After each hit the response period was terminated and a dipper mechanism presented $0.35 \mathrm{cc}$ of water. Failure to respond during the response period was scored as a miss and no water was given.

The S- interval was the interval lasting from the termination of the response period through the first $0.2 \mathrm{sec}$. of S+. The S- interval was automatically varied in duration after each hit. A response during the Sinterval, referred to as a $\mathrm{S}$ - response, did not actuate the dipper and added a period of varied duration to the S- interval.

Table 1 summarizes the procedural details and some of the behavioral results of the three experiments. In Experiment 3, for example, equal numbers of 15,20 , 25 , and $30 \mathrm{sec}$. S- intervals were used in scrambled order for both animal and human Ss. The delay for a $S-$ response was of $8,9,10,11$, or 15 sec.; the various durations of delay were used in scrambled order.
The duration of S+ was fixed at $1 \mathrm{sec}$, although a maximum of $3 \mathrm{sec}$. was allowed for the response period. The mean of $26 \mathrm{~S}$ - responses per session of 60 hits is an average of the data from both animals, as is the mean latency of $1.1 \mathrm{sec}$. For the two human Ss, the mean number of $S-$ responses and the mean latency were 16 and 0.7 sec., respectively.

The intensity of $\mathrm{S}+$ was controlled by a recording attenuator which in turn was controlled by the sequence of hits and misses. Each miss increased S+ intensity by 1 step, and S+ intensity was decreased by 1 step following 3 sequential hits. A further decrease of 1 step required 3 more sequential hits. In Experiments 1,2 , and 3 , the magnitudes of the steps were $3.2 \mathrm{~dB}$, $1.2 \mu \mathrm{A}$. , and $3.5 \mathrm{~dB}$ respectively. The performance measure used was the lowest $\mathrm{S}_{+}$intensity attained during each session.

\section{EXPERIMENT 1: AUDITORY MASKING}

\section{Method}

S+ was a train of $0.5 \mathrm{msec}$. rectangular pulses (clicks) at 40 pulses per sec. (pps) applied to a 4-in. Quam speaker. White noise, delivered by an Altec $755 \mathrm{C}$ speaker, was continuously present. Every session began with a S- interval followed by presentation of S+ at the maximum sound pressure level (SPL) permitted in that session. The four maximum S+ SPLs used were $50,60,70$, and $80 \mathrm{~dB}$ re .0002 dynes per $\mathrm{cm}^{2}$. The four noise SPLs used were numerically the same as the St SPLs. Sound-pressure-level measurements were made with a B \& K type 2203 sound level meter.

Each $\mathrm{S}$ was tested in three sessions at each of the four levels of masking noise. To permit a gross comparison between human Ss and guinea pigs, each of three humans was tested in a single session with both noise and maximum S+ SPLs of $80 \mathrm{~dB}$. With the door of the test chamber open, it was possible for the human $S$ to position his ears in the plane normally occupied by the guinea pig and also to manually operate the response device.

\section{Resulis}

In Fig. 1, three-session averages of lowest S+ SPL are plotted vs. SPL of the masking noise for each of the seven guinea pigs. Data obtained from Ss 2, 5, 7, and 8 can be fit by straight lines (not shown in Fig. 1) with slopes of unity. Consequently, for each of the four Ss, the difference was calculated between the lowest $\mathrm{S}_{+}$ and masking noise SPLs for each session, and the differences were averaged over the 12 sessions. The respective mean differences were $-14.4,-23.4,-23.9$, and $\mathbf{- 2 1 . 9} \mathrm{dB}$; the associated standard deviations were $3.4,2.6,3.2$, and $2.8 \mathrm{~dB}$.

Post-mortem inspection of the ears of Ss $5,7,8$, and 12 did not reveal any obvious abnormality. Examination of the middle ears of Ss 1, 2, and 9 with a Zeiss operation microscope revealed no abnormality in $\mathrm{S} 2$, fixation of the ossicles in $\mathrm{S} 9$, and absence of the ossicles and thickening of the middle ear membranes in $\mathrm{S} 1$. Of three 


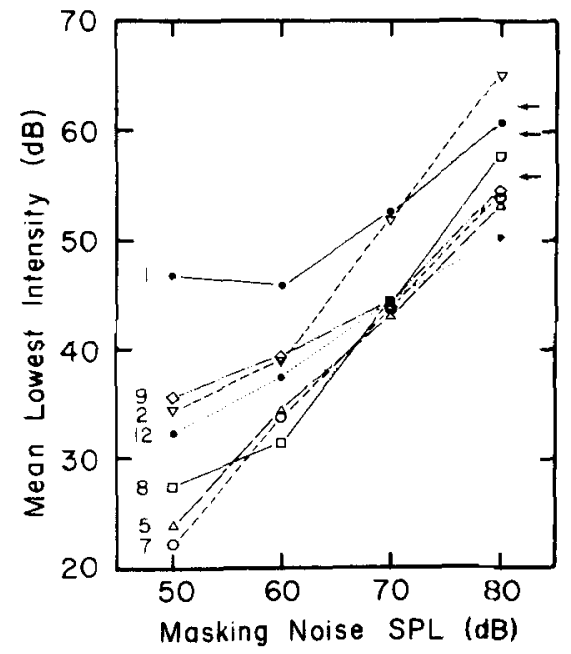

Fig. 1. Mean lowest $S+$ SPL as a function of masking noise SPL. Animal number is shown on the left, and the performance of three human $S s$ is indicated by arrows on the right.

Ss discarded before the start of formal testing, two had abnormal middle ears.

\section{EXPERIMENT 2: DETECTION OF BRAIN STIMULATION Method}

Multiple electrode arrays were implanted in Ss 30 , 31 , and 33 , four weeks before the start of threshold measurements. Each electrode array consisted of two sets of four stainless steel wires and an attached socket. Each wire was 0.005 in. in diameter and triple insulated with Formvar enamel except for the cross section of the tip. The electrodes in each set of four were staggered in length and gently twisted together for increased rigidity; the sets were spaced $2.5 \mathrm{~mm}$ apart. The electrode arrays were implanted stereotaxically and aimed for the region of the inferior or superior colliculus according to coordinates determined on other guinea pigs.

St was a train of negative pulses with each pulse of $1 \mathrm{msec}$. duration. Pulse separation, $\Delta t$, was either 80 or $800 \mathrm{msec}$. The pulses were applied to an electrode through a $10 \mathrm{mfd}$. capacitor which did not distort the waveform but insured a zero net transfer of charge, and through a 1 megohm resistor which in essence produced a constant current source. The amplitude of the pulses was controlled by a $40,000 \mathrm{ohm}$ linear potentiometer attached to the recording attenuator. During some of the sessions various acoustic stimuli were deliberately introduced, but as no effect on lowest intensity per session was observed, this variable will not be considered further. In this experiment, all sessions for a particular electrode and value of $\Delta t$ were completed before a different electrode or value of $\Delta t$ was used.

In Ss 30 and 33 after a series of 25 sessions (see results), a lesion was produced by an anodal direct- current of 0.2 ma passed for 10 sec.through electrodes $\mathrm{D}$ and $\mathrm{H}$ (see Table 2) while the animals were conscious. The Ss were tested immediately after the lesion and on the following day.

Electrodes were also implanted in Ss 1, 2, and 9 from Experiment 1. Thresholds for electrical stimulation were obtained using the behavioral procedures of Experiment 1, and a $100 \mathrm{cps}$ sinusoidal current as S+. The linear potentiometer controlled stimulus intensity.

\section{Results}

Table 2 summarizes the electrical stimulation data for all Ss. Guinea pig 1, for example, was tested using a single electrode with a $100 \mathrm{cps}$ sinusoid as $\mathrm{S}+$. The mean of the lowest current in each of the six sessions was $6.6 \mu \mathrm{A}$. and the standard deviation was $1.7 \mu \mathrm{A}$. The current was measured in terms of root mean square (rms) values for the sinusoidal stimulus. The pulsate stimuli used with Ss 30,31 , and 33 were measured in terms of peak current per pulse.

In the test session immediately following the lesions, the lowest current detected by $\mathrm{S} 33$ was $28.5 \mu \mathrm{A}$. while $\mathrm{S}$ 30 showed no sign of detecting current pulses of $60 \mu \mathrm{A}$. On the following day $S 33$ showed no sign of detecting $60 \mu \mathrm{A}$. pulses and S 30 showed no sign of detecting $100 \mu \mathrm{A}$. pulses,

\section{EXPERIMENT 3: SUMMATION OF AUDITORY STIMULATION Method}

S+ was a 1 sec. train of 0.5 msec. noise bursts generated by a noise source and a Grason-Stadler electronic switch set on "fast" rise time. The independent variable was the interval between bursts $(\Delta t)$; values of $10,32,100,320$, and $1000 \mathrm{msec}$. Were used. The corresponding numbers of bursts presented in each 1 sec. St period were 101,33,11, 4, and 2. Only one value of $\Delta t$ was used in each session although $\Delta t$ was varied in scrambled order from session to session.

Two guinea pigs, Ss 30 and 31 which had been used in the previous experiment, and two humans were tested.

Table 2. Experiment 2: Summary of Electrical Stimulation Data

\begin{tabular}{|c|c|c|c|c|c|}
\hline $\begin{array}{c}\text { Animal } \\
\text { No. }\end{array}$ & Ele & ctrode & $\begin{array}{l}\text { Mean lowest } \\
\text { current }(\mu \mathrm{A} .)\end{array}$ & $\begin{array}{c}\text { Standard } \\
\text { deviation } \\
(\mu \mathrm{A} .)\end{array}$ & $\begin{array}{l}\text { No. of } \\
\text { sessions }\end{array}$ \\
\hline$]$ & 100 eps sinusoid & A & $6.6(\mathrm{rms})$ & 1.7 (rms) & 6 \\
\hline 2 & i00 cps sinusoid & 8 & 11.1 (rms) & 2.2 (rms) & 6 \\
\hline 9 & 100 cps sinusoid & $c$ & $15.5(\mathrm{rms})$ & $2.3(\mathrm{rms})$ & 6 \\
\hline \multirow[t]{3}{*}{30} & $\Delta t=80 \mathrm{msec}$ & $\mathrm{D}$ & $\begin{array}{l}13.2 \\
(>60,>100) *\end{array}$ & 3.1 & $\begin{array}{l}25 \\
(2)\end{array}$ \\
\hline & $\Delta t=80 \mathrm{msec}$. & $E$ & 21.3 & 2.6 & 11 \\
\hline & $\Delta t=800 \mathrm{~m} \mathrm{sec}$ & $E$ & 28.9 & 2.6 & 9 \\
\hline \multirow[t]{3}{*}{31} & $\Delta t=80 \mathrm{msec}$ & $F$ & 27.3 & 5.6 & 25 \\
\hline & $\Delta t=80 \mathrm{~m} \mathrm{sec}$. & G & 7.0 & 2.2 & 11 \\
\hline & $\Delta t=800 \mathrm{msec}$ & G & 27.2 & 7.3 & 9 \\
\hline \multirow[t]{3}{*}{33} & $\Delta t=80 \mathrm{msec}$. & $\mathrm{H}$ & $\begin{array}{l}11.9 \\
(28.5,>60)^{*}\end{array}$ & 2.2 & $\begin{array}{l}25 \\
(2)\end{array}$ \\
\hline & $\Delta t=80 \mathrm{msec}$. & $J$ & 21.6 & 3.5 & 8 \\
\hline & $\Delta \Delta^{+}=800 \mathrm{msec}$. & J & 33.5 & 5.8 & 8 \\
\hline
\end{tabular}

* Numbers in parentheses refer to the 2 post-lesion sessions 


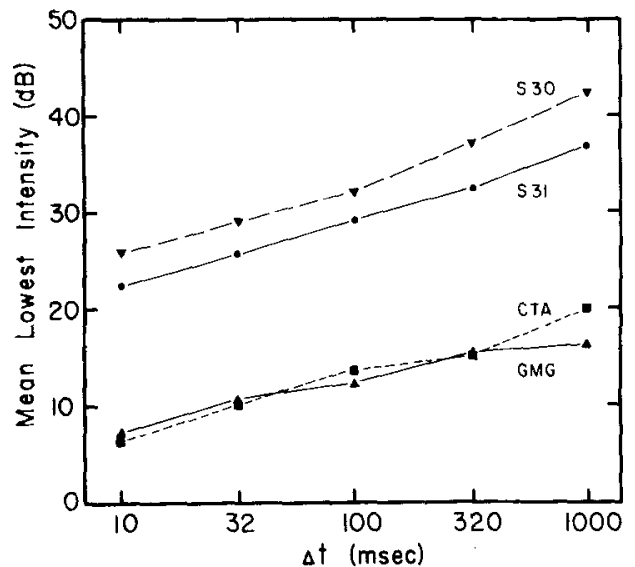

Fig. 2. Mean lowest $S_{+}$SPL as a function of the interval $(\Delta t)$ between $0.5 \mathrm{msec}$. noise bursts. The intensity of $S_{+}$is specified in terms of a continuous noise measured at the ear of $S$. The 0.5 msec. noise bursts are samples of the continuous noise.

Each human received two sessions for each value of $\Delta t$. Guinea pig 30 received either five or six sessions for each $\Delta t$, while $s 31$ received seven sessions for each $\Delta t$.

The human Ss were seated in a 7 by $8 \mathrm{ft}$. IAC sound booth $6 \mathrm{ft}$. from an Acoustic Research AR3ST speakerthe same speaker that was used with the guinea pigs. Human Ss responded by pressing a microswitch and received an auditory signal following a hit.

\section{Results}

The data from human Ss for the two sessions at each $\Delta t$ were averaged. With the data from the guinea pigs, it was possible to calculate the mean lowest intensity for each $\Delta t$ and the associated standard deviation. The mean lowest S+ SPLs for all Ss are shown in Fig. 2. The median of the standard deviations for $\mathrm{S} 30$ was $2.9 \mathrm{~dB}$;

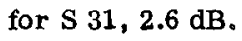

Post-mortem examination of the middle ears of $\mathrm{S} 31$ using the operation microscope revealed no abnormality. Manipulation of the ossicular chains gave no evidence of fixation.

\section{DISCUSSION}

Several factors seem of importance in training the guinea pig with operant procedures; namely, an adequate response device, isolation from extraneous stimulation, the presence of a masking noise in the early stages of training, and sufficient deprivation of water when water is used as the reinforcing stimulus. The absence of some of these factors would seem to account for reports of behavioral differences peculiar to the guinea pig (Glickman \& Hartz, 1964) and reports of difficulty in training the animal (Valenstein, 1959).

Operant threshold procedures (Blough, 1958; Clack \& Harris, 1963) typically demand reliable performance from $S$. In the present study, the regularly obtained standard deviations of several $\mathrm{dB}$ or several $\mu \mathrm{A}$. are indicative of the consistent behavior of the guinea pig. Four factors are viewed as responsible for the consistent behavior because collectively they make it un- likely that responding uncorrelated with the presence of S+ ("guessing") will step the attenuator downward. These factors are the criterion of three hits per downward step, the variability of the $S-$ interval, the variability of the delay following a $S$ - response, and the limited duration of $S+$. The small number of $S-$ responses occurring in Experiment 3 (see Table 1) is indicative of the low probability of reinforcement for guessing in this last version of the threshold procedure.

Gnawing behavior of the guinea pig still constitutes a problem (Valenstein, 1959). In the present study Ss gnawed on the plastic of the cage rather than on the response device; probably because S- responding postponed the possibility of obtaining reinforcement. Observation of Ss during test sessions frequently showed alternation of short periods of gnawing and of what looked like listening behavior.

It will be recalled that straight lines of unity slope fit the data obtained from $\mathrm{Ss} 2,5,7$, and 8 in Experiment 1. The data for Ss 1, 9, and 12 can also be fit by straight lines although with slopes significantly less than unity. Middle ear pathology was clearly demonstrated in Ss 1 and 9, and ossicular fixation would not have been detected in the visual inspection of the middle ears of S 12. The hypothesis suggested is that in the guinea pig, middle ear pathology is indicated by a masking function with a slope less than unity.

That thresholds could be obtained for all electrodes tested in Experiment 2 indicates the general usefulness of operant techniques in measuring detection of brain stimulation. That the neural elements mediating detection were in the vicinity of the electrodes is evidenced by the effect on detection of the small lesion-producing currents. The thresholds obtained for electrical stimulation are at the low end of the range reported by Nielson, Knight, and Porter (1962) for a variety of locations in the cat brain, but are above the thresholds reported for electrical stimulation of the auditory nerve in man (Simmons, Epley, Lummis, Guttman, Frishkopf, Harmon, \& Zwicker, 1965). Other factors, however, such as pulse duration, electrode area, and local cytoarchitecture, must also be considered. The threshold decreases obtained with Ss 30,31 , and 33 when pulse separations were decreased from $800 \mathrm{msec}$. to $80 \mathrm{msec}$., and the $10 \mathrm{msec}$. or less electrical time constants calculated by other investigators (see Ranck, 1963), together suggest that the threshold decrease was the result of the summation of neural activity rather than a local electrical effect.

In Experiment 3, the performance difference of approximately $20 \mathrm{~dB}$ between humans and guinea pigs seems significant in light of the similar guinea pig and human thresholds obtained in the presence of the $80 \mathrm{~dB}$ masking noise in Experiment 1. The performance difference could have been caused by slight fixation of the ossicular chain, by interspecies differences in sensitivity of the ear, by self-masking from gnawing, or by interspecies differences in the integration of 
broad-band stinuli: the data do not permit selection among these possibilities.

In the formulations of Plomp (1961), Zwislocki (1960), and Zwislocki, Hellman, and Verrillo (1962) on the summation of auditory stimulation, the excitation in the auditory system produced by a brief acoustic stimulus decays exponentially with a time constant on the order

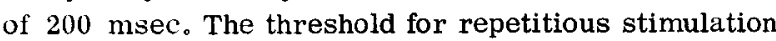
is lower than the threshold for a single stimulus because of summation of excitation. Lower thresholds were obtained in Experiment 3 with smaller values of $\Delta t$ as would be predicted from these formulations. There is only moderate agreement between the data of Experiment 3 and the threshold change calculated on the basis of Zwislocki's (1960) theory, but the broad spectrum of the noise bursts used as S+ may account for this (Zwislocki et al, 1962).

An interpretation based on summation of stimulation is favored by the present author, but two additional factors may be of importance. First, although the problem is not unique to the present study, it cannot be ascertained whether S maintained a constant criterion for responding over the range of $\Delta t$ values. Second, a probabilistic interpretation may also be in order. As $\Delta t$ was decreased, the number of noise bursts presented during S+ increased. To the extent that the detection of each noise burst is independent of the detection of the other noise bursts, increasing the number of bursts will increase the probability of detecting $\mathrm{S}_{+}$, and hence, produce a lower threshold. These considerations are most likely important for $\Delta t$ values of 1000 and 320 msec. Apart from the interpretation of the data, however, operationally similar testing procedures used with human Ss and with guinea pigs produce threshold functions of similar form.

Middle ear malfunction in the guinea pig proved to be more bothersome than had been anticipated on the basis of the reports in the literature. A series of 41 additional Ss was used in an attempt to assess the seriousness of the problem. Procedures included recording of auditory evoked responses, measurement of pinna reflex to sound stimuli, gross and microscopic examination of middle ears, and preparation of stained sections of middle ears. These results will be presented elsewhere; at present, it can be stated that the proportion of abnormal ears observed in Experiment 1 was not atypical.

\section{References}

Blough, D. S, A method for obtaining psychophysical thresholds from the pigeon. $J$. exp. Anal. Behav., 1958, 1, 31-43.

Clack, T. D., \& Herman, P. N. A single-lever psychophysical adjustment procedure for measuring auditory thresholds in the monkey. J. aud. Res., 1963, 3, 175-183.

Diamond, I. T., \& Neff, W. D. Ablation of temporal cortex and discrimination of auditory patterns. J. Neurophysiol., 1957, $20,300-315$

Glickman, S. E., \& Hartz, K. E. Exploratory behavior in several species of rodents. J. comp. physiol. Psychol., 1964, 58, 101104.

Miller, J. D. Personal communication, 1964.

Nielson, H. C., Knight, J. M., \& Porter, P. B. Subcortical conditioning, generalization, and transfer. J. comp. physiol. Psychol., 1962, 55, 168-173.

Plomp, R. Hearing threshold for periodic tone pulses. J. Acoust. Soc. Amer., 1961, 33, 1561-1569.

Ranck, J. B. Jr. Analysis of specific impedance of rabbit cerebral cortex. Exp. Neurol., 1963, 7, 153-174.

Simmons, F. B., Epley, J. M., Lummis, R. C., Guttman, N., Frish kopf, L. S., Harmon, L. D., \& Zwicker, E. Auditory nerve: electrical stimulation in man. Science, 1965, 148, 104-106.

Valenstein, E. S. The effect of reserpine on the conditioned emotional response in the guinea pig. J. exp. Anal. Behat., 1959, $2,219-225$

Watson, C. S. Masking of tones by noise for the cat. $J$. Acoust Soc. Amer., 1963, 35, 167-172.

Zwislocki, J. Theory of temporal auditory summation. J. Acoust. Soc. Amer., 1960, 32, 1046-1060.

Zwislocki, J., Hellman, R. P., \& Verrillo, R. T. Threshold of audibility for short pulses. J. Acoust. Soc. Amer., 1962, 34, 1648-1652.

Note

1. The author is grateful to $\mathrm{Dr}$. White $\mathrm{McK}$. Wallenborn for performing the middle ear examinations of guinea pigs Nos. 1, 2, 9 , and 31. The study was supported in part by Grant $M H 6647$ from the National Institute of Mental Health, U. S. Public Health Service.

(Received in the Editorial Office March 11, 1966.) 